\title{
Brief Communication Simple mathematical and computational wear model for ultra-high-molecular-weight polyethylene total hip replacements
}

\author{
K. H. S. Chan' ${ }^{1}$, T. Pearce ${ }^{2}$, R. W. Blake ${ }^{1}$, L. Chow ${ }^{1}$, S. Wu' ${ }^{1}$, \\ F. Wong ${ }^{1}$ and J. Li ${ }^{1}$ \\ ${ }^{1}$ Department of Zoology, University of British Columbia, Vancouver, British Columbia, Canada V6T $1 Z 4$ \\ ${ }^{12}$ Committee on Evolutionary Biology, University of Chicago, Chicago, IL 60637
}

\begin{abstract}
Ultra-high-molecular-weight polyethylene is an important constituent of hip implants. Surgical revisions are required because of implant loosening and osteolysis (destruction or resorption of bone tissue). We develop a mathematical and a computational model to determine implant life (defined as the time when $20 \%$ of the implants operating at a given wear rate is revised) based on wear rates and apply them to the data of Sochart (Clin Orthop Relat Res, 363:135-50, 1999). No significant difference was found between mathematical and computational model predictions (14.8 and 14.7 years, respectively) from the actual value of $15.0 \pm 3.9$ years $(\bar{X} \pm 2 S E ; P>0.05)$. We find that an increase in cross-linking does not decrease implant life greatly. However, a large decrease in implant life occurs with an increase in surface roughness, cycles per year and body weight or a decrease in contact stress and femoral head radius.
\end{abstract}

Key words: UHMWPE hip replacement, implant life, wear model

\section{INTRODUCTION}

Ultra-high-molecular-weight polyethylene (UHMWPE) is used for total joint arthroplasty (Wang et al. 1995, 1998; Scholes et al. 2000; Wang 2001; Endo et al. 2002; Lewis et al. 2003). Evidence suggests that it is linked to osteolysis (destruction or resorption of bone tissue; Willert et al. 1977, 1990; Schmalzried et al. 1992; McKellop et al. 1995; Wirth et al. 1999; Mabrey et al. 2002). Research has focused on wear rates of UHMWPE by different material parameters (e.g. molecular weight between cross-links [Wang 2001], femoral head roughness [Wang et al. 1998], coefficient of friction, contact stress [Wang et al. 2001], tensile toughness, crystallinity and protein concentration [Lewis et al. 2003]). Ninety percent of implants survive for more than 10 years (Cornell and Ranawat 1986; Skeie

Corresponding Author:

K. H. S. Chan

Department of Zoology

University of British Columbia

Vancouver, British Columbia

Canada V6T 1 Z4

Tel: + 1-604-822-3373

Fax: + 1-604-822-2416

Email: keithhsc@interchange.ubc.ca et al. 1991; Kavanagh et al. 1994; Marston et al. 1996) and their subsequent failure is commonly due to implant loosening associated with high torque around the stem axis from forces and moments acting on the hip prostheses (Bergmann et al. 1995). The onset of patient pain is a means of detecting prosthetic loosening, requiring implant revision surgery. It is important to detect acetabular loosening early to minimize the degree of bone loss (Sochart 1999).

As far as we are aware, no mathematical or computational relationships between implant revisions and wear rates have been developed. We develop a simple mathematical and computational model for predicting the life of an implant given a set of material and patient parameters. Model results are applied to implant survival of acetabular cups with time from Sochart (1999), allowing for the calculation of implant life ( $I$; defined as the time when $20 \%$ of the implants operating at a given wear rate are revised) based on a given wear rate.

General wear is given by

$$
k=\frac{V p}{l x}
$$

where $k, V, x, l$ and $p$ are wear factor, volume of wear, sliding distance, load and hardness of the bearing surface, respectively (Rabinowicz 1995). In biomedical engineering, 
volumetric wear rate is corrected for loading and sliding distance and $k$ is

$$
k=\frac{V}{F S}
$$

where $F=\alpha m g$ and $m$, body mass (assuming a patient of $82 \mathrm{~kg}), g$, acceleration due to gravity $\left(9.8 \mathrm{~m} / \mathrm{s}^{2}\right)$ and $\alpha=$ 3.5 , reflecting the 'true' load on the femoral head that may reach levels of 6-8 if the patient is running or ascending stairs (Bergmann et al. 1993, 1995). The sliding distance per cycle $(S)$ is

$$
S=2\left(\frac{2 \pi r \theta}{360^{\circ}}\right) \times 10^{-3}
$$

where $\theta$ is the gait angle in degrees $\left(40^{\circ}\right.$; Nordin and Frankel 2001) and $r$ is the femoral head radius $(13 \mathrm{~mm})$.

The wear factor depends on the molecular weight between cross-links $\left(M_{c}\right)$ :

$$
k_{1}=0.0003\left(M_{\mathrm{c}}-4258\right) \times 10^{-6}
$$

where $M_{\mathrm{c}}=6200 \mathrm{~g} / \mathrm{mol}$ (Wang 2001) and the femoral head roughness $\left(R_{a}\right)$ :

$$
k_{2}=0.00000721 R_{a}^{0.411}
$$

where $R_{a}=0.1 \mu \mathrm{m}$ (Wang et al. 1998). The coefficient of friction $(\mu)$ is

$$
k_{3}=0.000245 \mu^{2}
$$

where $\mu=0.07$ (Wang et al. 2001). Contact stress $(\sigma)$ is given by

$$
k_{4}=0.00000799 \sigma^{-0.653}
$$

where $\sigma=5.3 \mathrm{MPa}$ (Wang et al. 2001). The tensile toughness $(U)$, crystallinity $(C)$ and protein concentration $(P)$ are

$$
k_{5}=460 U^{0.72} C^{-5.29} P^{-0.66}
$$

where $U, C$ and $P$ are $140 \mathrm{MJ} / \mathrm{m}^{3}, 49 \%$ and $45 \%$ (Lewis et al. 2003). The average wear rate $k_{a}$ is

$$
k_{a}=\frac{k_{1}+k_{2}+k_{3}+k_{4}+k_{5}}{5}
$$

and the volume of wear is

$$
V=k_{a} F S
$$

Multiplying by the number of cycles per year $(N, 1.4 \times$ $10^{-6}$; Goldsmith et al. 2001) gives the volumetric wear rate $(W)$ :

$$
W=V N=k_{a} F S N
$$

Dividing the volumetric wear rate by the area of a circle of area corresponding to acetabular cup gives the linear wear rate $(L)$ :

$$
L=\frac{k_{a} F S N}{\pi r^{2}}
$$

The relationship between implant time and wear rate (Sochart 1999, Figure 5) is

$$
I=-40(L)+22
$$

$\left(r^{2}=0.95\right)$. Substitution gives

$$
I=-40\left(\frac{k_{a} F S N}{\pi r^{2}}\right)+22
$$

We created a replica of the femoral head of an acetabular cup. A cross-sectional photograph of the porcelain mixture was used to map the motion of the femoral head. The centre of the initial femoral head position was derived from the intersection of perpendicular lines drawn from the left side of the curvature (Fig. 1a). We repeated this on the bulge side (right side) to determine the centre of the final femoral head position. The radius of curvature increases initially followed by a decrease suggesting two regions of wear: pretunnelling wear $(y)$ and tunnelling wear $(x)$ (Fig. 1). The volume due to pre-tunnelling wear $V_{y}$ is

$$
V_{y}=\frac{1}{4} V_{x+y}
$$

and that of tunnelling wear $\left(V_{x}\right)$ is

$$
V_{x}=V_{x+y}-\frac{1}{4} V_{x+y}=\frac{3}{4} V_{x+y}
$$

Consequently, the linear wear rate (proportional to volume) is multiplied by a factor $\beta=0.75$ :

$$
I=-40\left(\frac{\beta k_{a} F S N}{\pi r^{2}}\right)+22
$$

A computational model was developed using artificial neural networks and applied to the data of Sochart (1999). The neural networks consist of McCulloch-Pitts neuron layers of non-linear differentiable activation functions, input, output and hidden layers. Each neuron at a given layer is connected to every neuron in the next layer (see Li et al. in press for details). Many configurations (1-3 layers; $1-10$ neurons) of the network (trained with error back propagation algorithm and momentum learning using $90 \%$ of the data) were tested with $10 \%$ of the data to obtain the optimal network configuration with the least mean sum of error $(\mathrm{Li}$ et al. in press). This was characterized by 1 hidden layer of 4 neurons, momentum factor of 0.7 , learning rate of 1.0 , 
$\mathbf{A}$

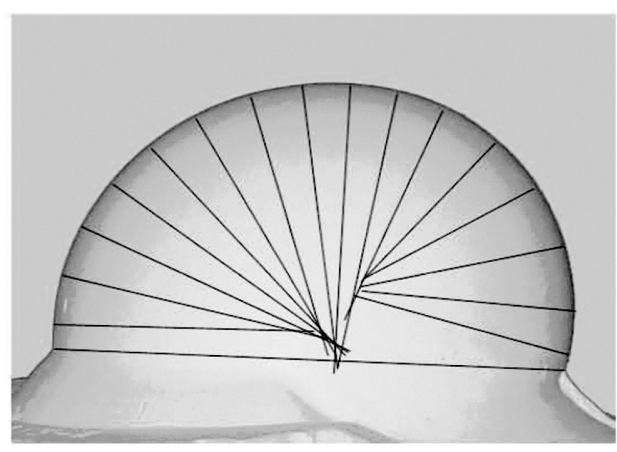

B
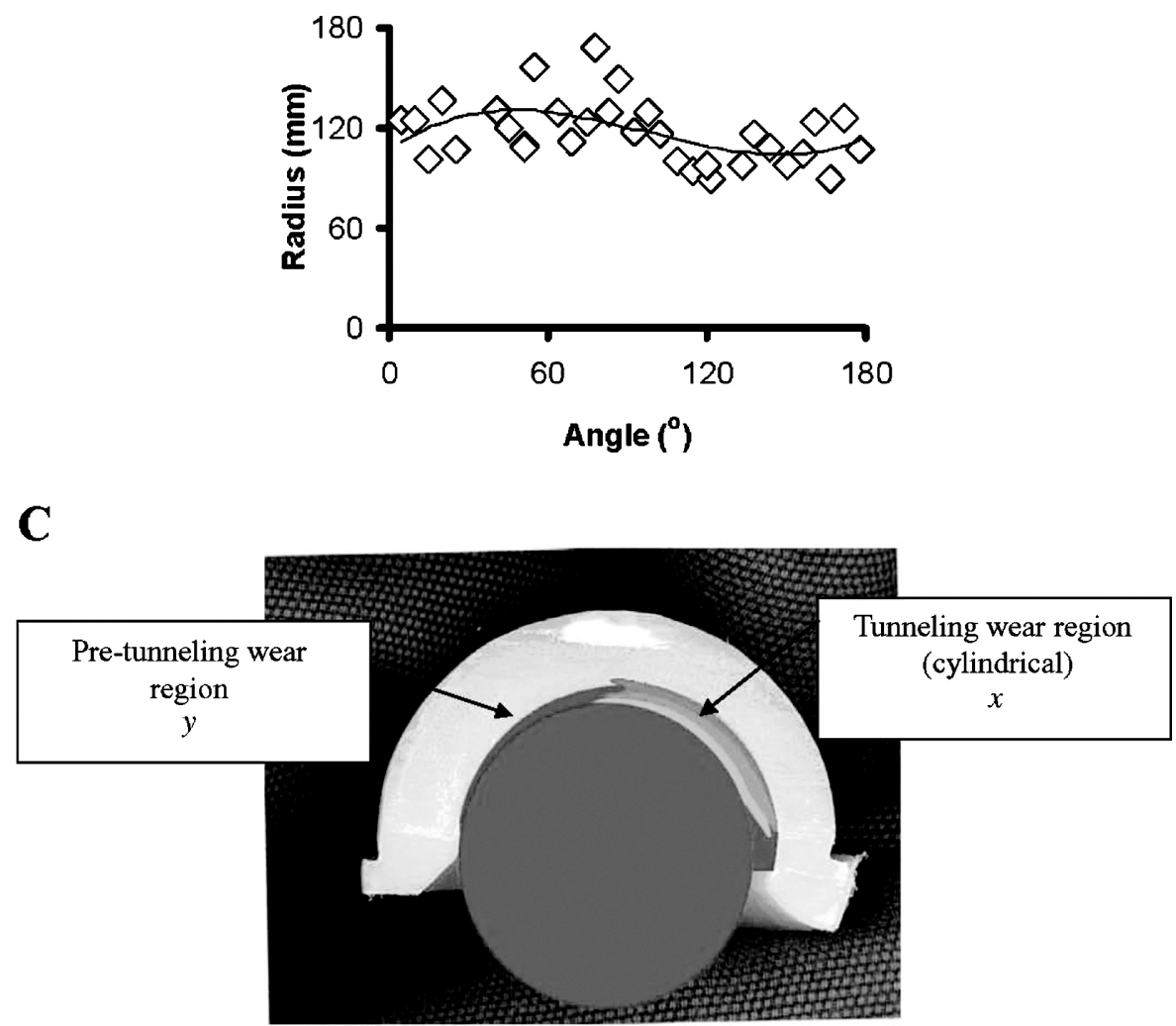

Figure 1 Acetabular cup (a) with perpendicular lines drawn from left to right (the bulge side). (b) The corresponding radius curvature suggests two regions of wear (c): pre-tunnelling $(y)$ and tunnelling wear $(x)$.

sum of error threshold of 0.01 and maximum number of epochs of 10,000 .

The implant lives of 14.8 and 14.7 years predicted from our mathematical and computation models, respectively, are not significantly different $(P>0.05)$ from the measured value of $15.0 \pm 3.9$ years $(\bar{X} \pm 2 \mathrm{SE}$; Sochart 1999). We find that an increase in molecular weight between cross-links does not decrease implant life greatly (Fig. 2). This has not been demonstrated in other studies where the molecular weight between cross-links is plotted against $k$ and not implant life (e.g. Muratoglu et al. 1999; Wang 2001). Wear rate increases with molecular weight between cross-links associated with a higher degree of rupture. However, cross-linked polyethylenes have a 30\% lower wear rate than non-cross-linked polyethylenes because cross-linking reduces the toughness of UHMWPE, which is inversely related to wear rate (Lancaster 1969; Endo et al. 2002). A large decrease in implant life occurs with an increase in surface roughness, cycles per year and body weight or a decrease in contact stress and femoral head radius (Fig. 2). The positive relationship between contact stress and implant life is consistent with decreasing wear rate and coefficient of friction (Wang et al. 2001). Muratoglu et al. (1999) argued that wear rate is independent 

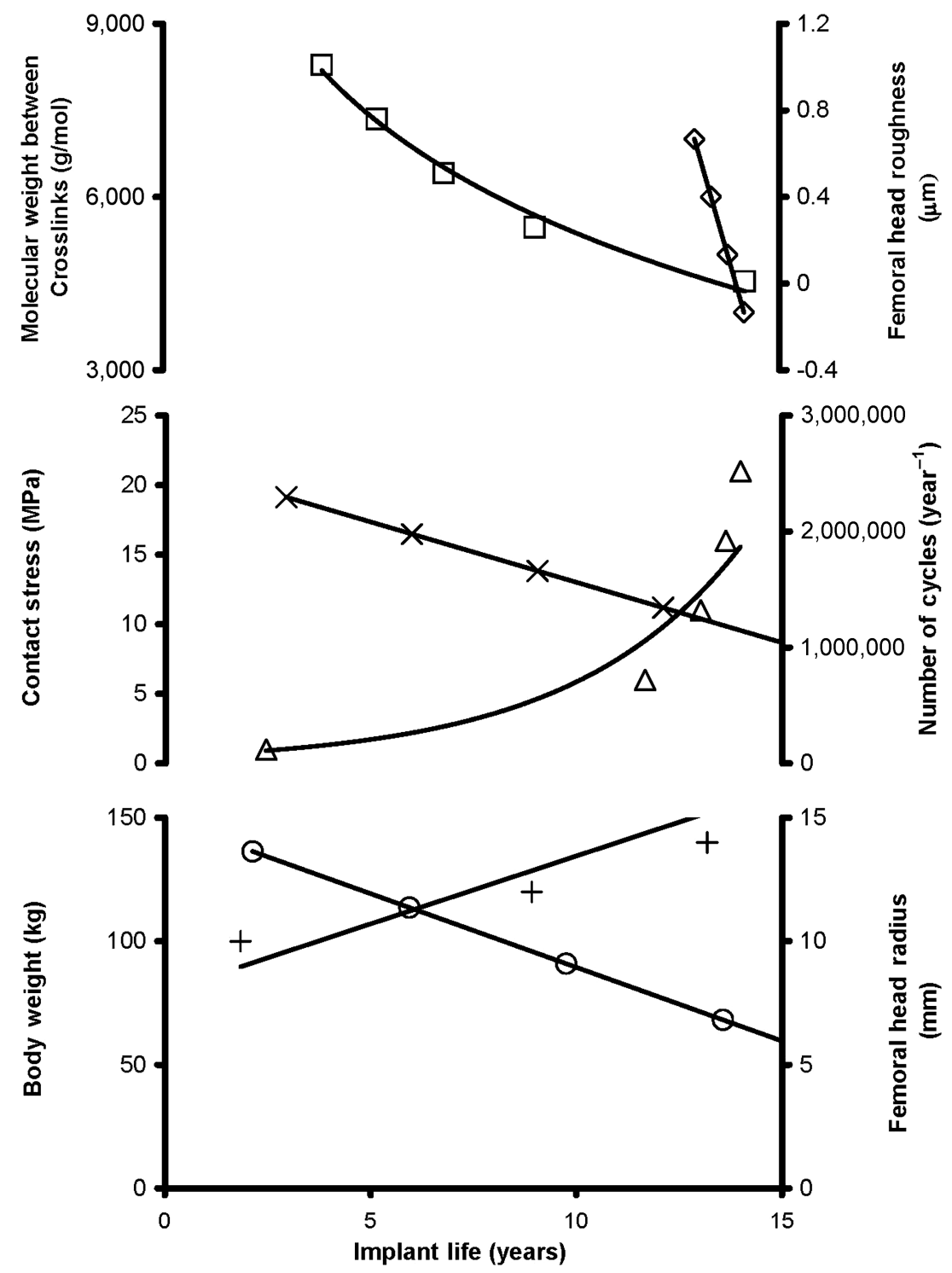

Figure 2 Molecular weight of cross-links (empty diamond), femoral head roughness (empty square), contact stress (empty triangle), number of cycles per year $(X)$, body weight (empty circle) and femoral head radius $(+)$ versus implant life.

of surface roughness. This is true only when $k_{2}$ is considered. However, a smooth femoral head is associated with a longer implant life when all parameters are considered. Patients should be discouraged from endurance exercise as cycles per year decrease implant life.

Wear path has been assumed to be cylindrical (femoral head travels from its initial to final position linearly; e.g. Devane et al. 1995, 1997; Martell et al. 2003). However, when the final femoral head position was determined from the bulge side (right side) of the curvature, the radius of curvature in region $y$ produces a sphere greater than the femoral head and does not support the linear movement hypothesis of the femoral head because its motion would have to be circular to produce such a curvature in the polyethylene cup from pre-tunnelling and tunnelling wear (Fig. 1).
The initial direction of load deviates from vertical due to the orientation of the implant and mediolateral and anterior-posterior forces in the hip joint during walking (Van Den Bogert et al. 1999). The femoral head moves in the direction of the load (Fig. 3A). On the left side, the contact area between the polyethylene cup and the femoral head is reduced over time and the effective direction of load deviates further from the vertical (Fig. 3B). As the contact area continues to decrease (Fig. 3C), the direction of the load may reach a point where pre-tunnelling wear becomes tunnelling wear (Fig. 3D). This occurs near the end of the implant life when the femoral head is close to its final position. Our proposed mechanism of wear path (Fig. 3E) possibly explains why two-dimensional analysis of wear fails to detect $25 \%-50 \%$ of prosthetic hip wear since there are two regions of wear rather than one. 


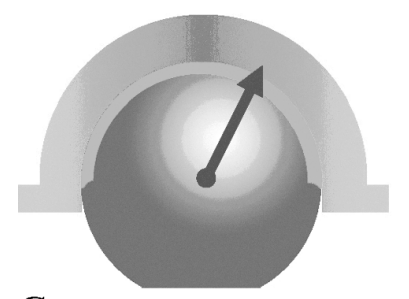

C

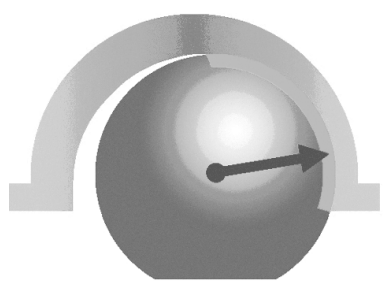

E

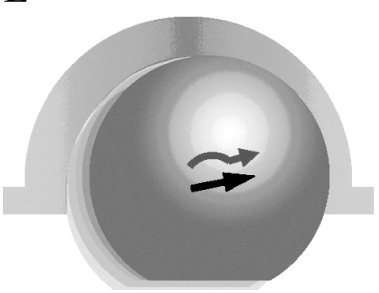

B

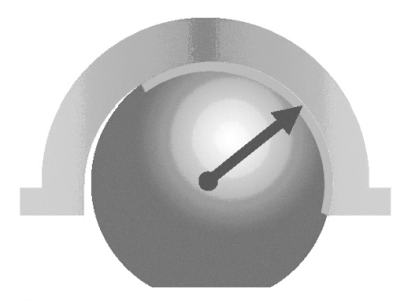

D

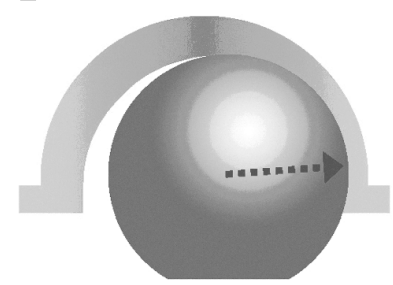

Figure 3 (a) The femoral head moves in the direction of the load. (b) On the left side, the contact area between the polyethylene cup and the femoral head is reduced over time and the effective direction of load deviates further from the vertical. (c) The contact area continues to decrease. (d) The direction of the load may reach a point where pre-tunnelling wear becomes tunnelling wear. (e) Total cylindrical wear (black arrow) and our proposed circular mechanism of wear with time (red arrow).

\section{ACKNOWLEDGMENTS}

We thank Drs. G. Fernlund and R. Wang and two anonymous reviewers for comments on an earlier version of this manuscript.

\section{REFERENCES}

Bergmann G, Graichen F, Rohlmann A. 1993. Hip joint during walking and running, measured in two patients. 7 Biomech, 26:969-90.

Bergmann G, Graichen F, Rohlmann A. 1995. Is staircase walking a risk for the fixation of hip implants? 7 Biomech, 28:535-53.

Bragdon CR, O'Connor DO, Lowenstein JD, Jasty M, Syniuta WD. 1996. The importance of multidirectional motion on the wear of polyethylene. Proc Inst Mech Eng Pt H J Eng Med, 210:157-66.

Cornell CN, Ranawat CS. 1986. Survivorship analysis of total hip replacements. F Bone Foint Surg, 68A:1430-34.

Devane PA, Bourne RB, Rorabeck CH, MacDonald S, Robinson EJ. 1995. Measurement of polyethylene wear in metal-backed acetabular cups. II. Clinical application. Clin Orthop, 319:317-26.

Devane PA, Robinson EJ, Bourne RB, Rorabeck CH, Nayak NN, Horne JG. 1997. Measurement of polyethylene wear in acetabular components inserted with and without cement. A randomized trial. 7 Bone foint Surg, 79:682-9.

Endo M, Tipper JL, Barton DC, Stone MH, Ingham E, Fisher J. 2002. Comparison of wear, wear debris and functional biological activity of moderately crosslinked and non-crosslinked polyethylenes in hip prostheses. Proc Inst Mech Eng, 216:111-22.

Goldsmith AA, Dowson D, Wroblewski BM, Siney PD, Fleming PA, Lane JM. 2001. The effect of activity levels of total hip arthroplasty patients on socket penetration. $\mathcal{F}$ Arthroplasty, 16:620-7.

Kavanagh BF, Wallrichs S, Dewtiz M, Berry D, Currier B, Ilstrup D, Coventry MB. 1994. Charnley low-friction arthroplasty of the hip. Twenty year results with cement. $\mathcal{F}$ Arthroplasty, 9:229-34.

Lancaster JR. 1969. Relationships between wear of polymer and their mechanical properties. Proc Inst Mech Eng, 183:98-106.

Lewis G, Fencl RM, Carroll M, Collins T. 2003. The relative influence of five variables on the in vitro wear rate of uncrosslinked UHMWPE acetabular cup liners. Biomaterials, 24:1925-35.

Li J, Chan KHS, Blake RW, Kwok PYL. In press. Biomechanical modeling with multilayer perception neural networks: a case study of undulatory median fin swimming in the knifefish Xenomystus nigri. $\mathcal{F}$ Fish Biol.

Mabrey JD, Afsar-Keshmiri A, Engh GA, Sychterz CJ, Wirth MA, Rockwood CA, Agrawal CM. 2002. Standardized analysis of UHMWPE wear particles from failed total joint arthroplasties. 7 Biomed Mater Res B (Appl Biomater), 63:475-83.

Marston RA, Cobb AG, Bentley G. 1996. Stanmore compared with Charnley total hip replacement. $\mathcal{F}$ Bone Foint Surg, 78B:178-84.

Martell JM, Berkson E, Berger R, Jacobs J. 2003. Comparison of two and three-dimensional computerized polyethylene wear analysis after total hip arthroplasty. F Bone foint Surg, 85A:1111-7.

McKellop HA, Campbell P, Park SH, Schmalzried TP, Grigoris P, Amstutz HC, Sarmiento A. 1995. The origin of submicron polyethylene wear debris in total hip arthroplasty. Clin Orthop, 311:3-20.

Muratoglu OK, Bragdon DR, O'Connor DO, Jasty M, Harris WH, Gul R, McGarry F. 1999. Unified wear model for highly crosslinked ultra-high molecular weight polyethylenes (UHMWPE). Biomaterials, 20:1463-70.

Nordin M, Frankel VH. 2001. Biomechanics of the hip. In Nordin M, Frankel VH, eds. Basic Biomechanics of the Musculoskeletal System. Philadelphia: Lippincott Williams \& Wilkins, p. 201-21.

Robinowicz E. 1995. Friction and Wear of Materials. New York: John Wiley \& Sons.

Schmalzried TP, Kwong LM, Jasty M, Sedlacek RC, Haire TC, O'Connor DO, Bragdon CR, Kabo JM, Malcolm AJ, Harris WH. 1992. The mechanism of loosening of cemented acetabular components in total hip arthroplasty. Analysis of specimens retrieved at autopsy. Clin Orthop, 274:60-78.

Scholes SC, Unsworth A, Goldsmith AA. 2000. A frictional study of total hip joint replacements. Phys Med Biol, 48:3721-35.

Skeie S, Lende S, Sjoberg E, Vollset SE. 1991. Survival of the Charnley total hip arthroplasty with cement after a minimum twenty year follow-up. 7 Bone Foint Surg, 75A:961-975. 
Sochart DH, 1999. Relationship of acetabular wear to osteolysis and loosening in total hip arthroplasty. Clin Orthop Relat Res, 363:135-50.

Van Den Bogert AJ, Read L, Nigg BM. 1999. An analysis of hip joint loading during walking, running, and skiing. Med Sci Sports Exerc, 31:131-42.

Wang A. 2001. A unified theory of wear for ultra-high molecular weight polyethylene in multi-directional sliding. Wear, 248:38-47.

Wang A, Essner A, Klein R. 2001. Effect of contact stress on friction and wear of ultra-high molecular weight polyethylene in total hip replacement. Proc Inst Mech Eng, 215:133-9.

Wang A, Essner A, Polineni VK, Stark C, Dumbleton JH. 1998. Lubrication and wear of ultra-high molecular weight polyethylene in total joint replacements. Tribol Int, 31:17-33.

Wang A, Polineni VK, Essner A, Sokol M, Sun DC, Stark C, Dumbleton JH. 1997. The significance of non-linear motion in the wear screening of orthopaedic implant materials. $\mathcal{F}$ Testing Eval, 25:239-45.
Wang A, Sun DC, Stark C, Dumbleton JH. 1995. Wear mechanisms of UHMWPE in total joint replacements. Wear, 181-183:241-9.

Wang A, Sun DC, Stark C, Dumbleton JH. 1996. Wear testing based on unidirectional motion: fact or artefact? In Proceedings of the 5th World Biomaterials Congress. Toronto, Ontario, Canada: University of Toronto Press, p. 1583.

Willert HG, Bertram H, Buchhorn GH. 1990. Osteolysis in alloarthroplasty of the hip. The role of ultra-high molecular weight polyethylene wear particles. Clin Orthop, 258:95-107.

Willert HG, Semlitsch M. 1977. Reactions of the articular capsule to wear products of artificial joint prostheses. 7 Biomed Mater Res, 11:157-64.

Wirth MA, Agrawal CM, Mabrey JD, Dean DD, Blanchard CR, Miller MA, Rockwood CA. 1999. Isolation and characterization of polyethylene wear debris associated with osteolysis following total shoulder arthroplasty. 7 Bone foint Surg, 81:29-37. 

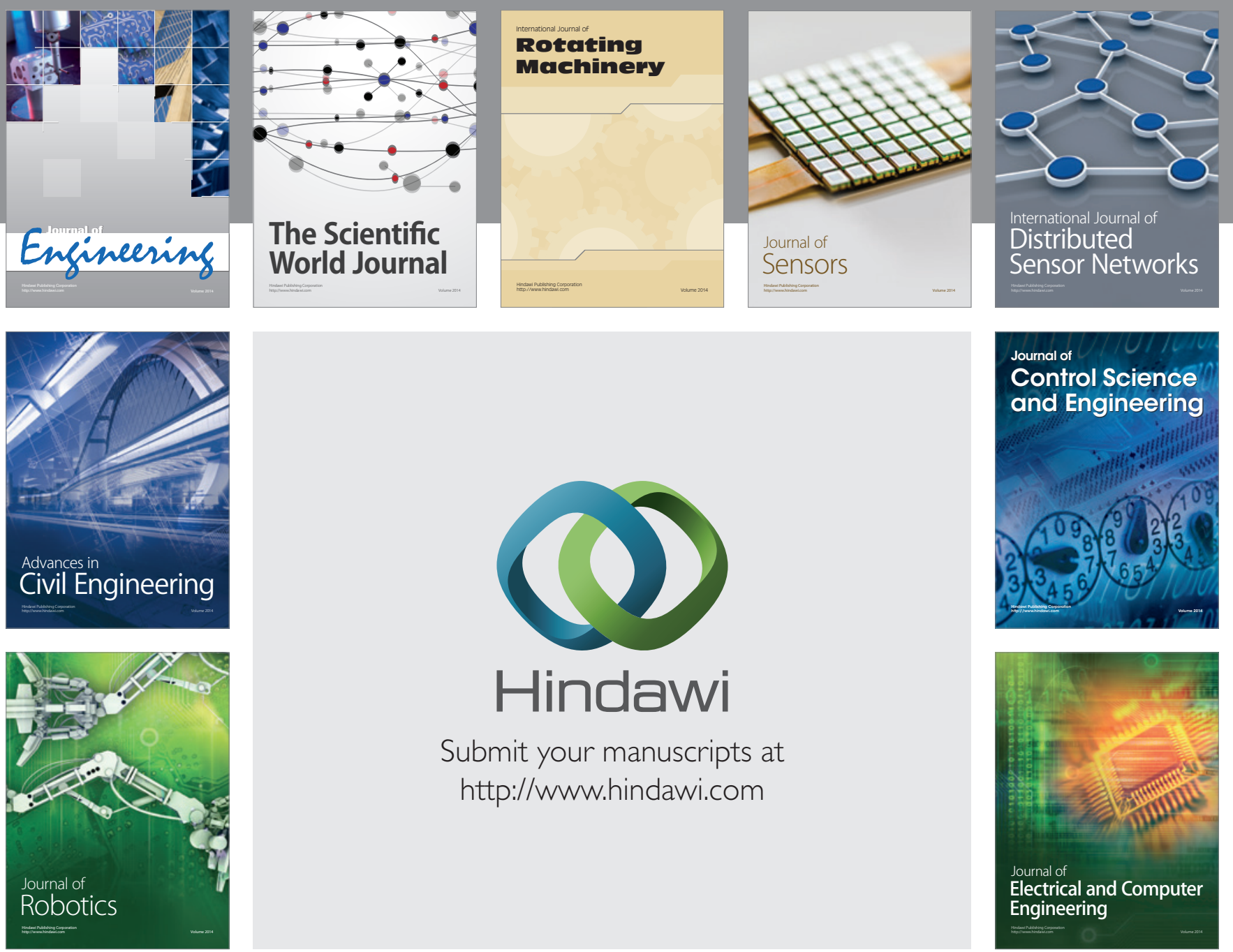

Submit your manuscripts at

http://www.hindawi.com
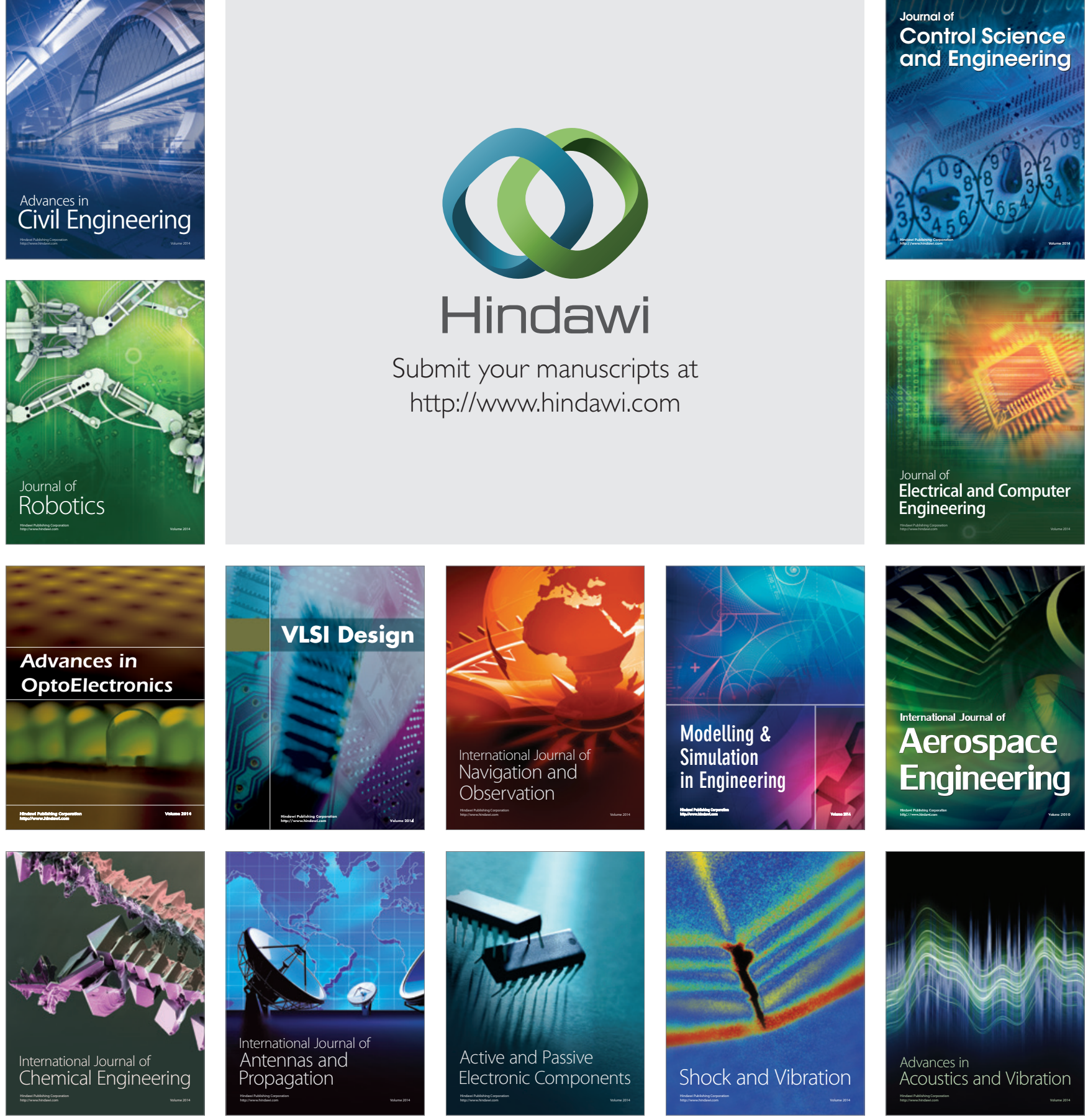